\title{
MELHORIA NA PRODUTIVIDADE NOS PROCESSOS DE PINTURA DE TANQUES NA CONSTRUÇÃO NAVAL *
}

\author{
Alexsander dos Santos e Santos ${ }^{1}$ \\ Fábio Luis Gasparini ${ }^{2}$ \\ Leonardo Guerra de Almeida ${ }^{3}$ \\ Karl Kristian Bagger ${ }^{4}$
}

\section{Resumo}

A construção naval sofreu nos últimos 40 anos várias mudanças de acordo com os diferentes cenários econômicos. O Brasil neste setor chegou a ocupar o segundo lugar na produção mundial, foi fortemente afetado pela crise recente. Diante desta conjuntura as empresas tem que otimizar seus processos visando um aumento na produtividade para se manter competitivas. A atividade da construção naval é complexa, tem várias etapas que geram interferências que muitas vezes impossibilitam trabalhos em paralelo. As chapas de aço que constituem as partes principais da embarcação, as estruturais, devem passar por um tratamento de preparação da superfície que inclui a sua pintura e proteção anticorrosiva, este é um dos processos mais críticos. Esta etapa além de demandar serviços muito especializados há ainda um aspecto agravante o ambiente confinado, que expõe os operários executantes a condições ergonômicas desfavoráveis proporcionando um rendimento baixo afetando diretamente a produtividade do processo. Este estudo realizou uma analise do processo e propôs as alterações nas etapas de fabricação eliminando os problemas proporcionando melhores condições de trabalho dessa forma minimizando o impactos ergonômicos, proporcionando redução de custo e aumento da produtividade.

Palavras-chave: Tratamento de Superfície. Tanques. Melhorar Produtividade. Custos.

\section{PRODUCTIVITY INCREASE IN TANKS PAINTING ON PROCESS OF SHIPBUILDING Abstract}

Shipbuilding has undergone several changes in the last 40 years according to different economic scenarios. Brazil in this sector came to occupy the second place in world production, was strongly affected by the recent crisis. Given this situation, companies have to optimize their processes in order to increase productivity in order to remain competitive. The activity of shipbuilding is complex, it has several stages that generate interferences that often make it impossible to work in parallel. The steel sheets that make up the main parts of the vessel, the structural parts, must undergo a surface preparation treatment that includes their paint and anticorrosive protection, this is one of the most critical processes. This stage, in addition to demanding very specialized services, also has an aggravating aspect of the confined environment, which exposes the performing workers to unfavorable ergonomic conditions, providing a low yield, directly affecting the productivity of the process. This study carried out a process analysis and proposed the changes in the manufacturing stages eliminating the problems, providing better working conditions in this way, minimizing the ergonomic impacts, providing cost reduction and increased productivity.

Keywords: Surface Treament; Shipbuilding; Productivity Increase; Produtividade. Cost reduction.

Formando em Engenharia da UNIMONTE; Santos, SP, Brasil.

Formando em Engenharia da UNIMONTE; Santos, SP, Brasil

Formando em Engenharia da UNIMONTE; Santos, SP, Brasil.

Professor Assistente, Orientador TCC do Departamento Engenharia UNIMONTE, Santos SP. 


\section{INTRODUÇÃO}

O surgimento da indústria naval brasileira aconteceu no final do século XIX. A implantação da construção naval brasileira, em larga escala, teve origem nos anos seguintes ao fim da Segunda Guerra Mundial. Neste momento, a indústria passou por transformações estruturais decisivas no país, em especial no governo Juscelino Kubitschek (1956-1961) através do Plano de Metas, caracterizado pelo comprometimento do setor público com uma política de desenvolvimento industrial. Até 0 ano de 1955, toda a indústria de construção naval se resumia em alguns estaleiros capazes de produzir apenas pequenas embarcações e realizar reparos.

Gráfico 01 - Evolução do emprego, transformações e políticas na Construção Naval Brasileira - entre 1960 e 2010.

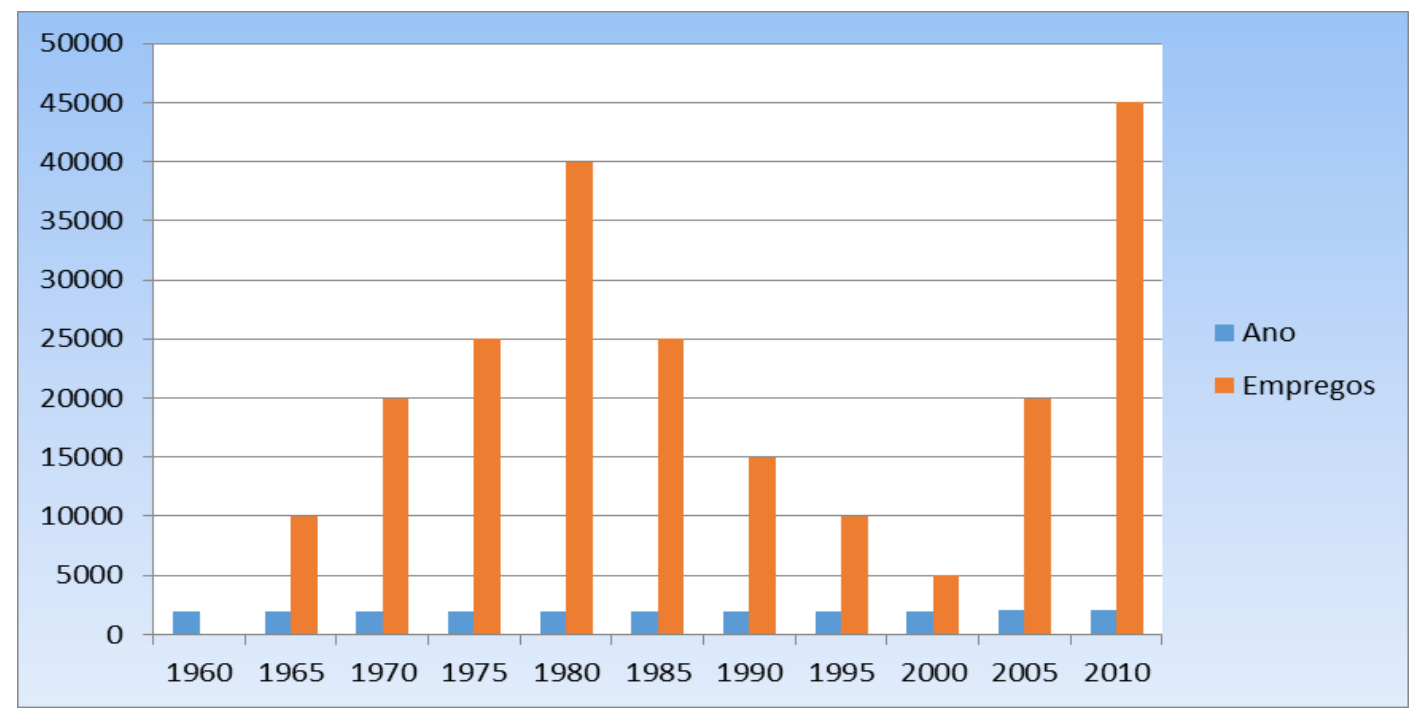

Fonte: Favarin (2009) adaptado.

Ao longo do tempo o setor teve períodos distintos após seu desenvolvimento. $\mathrm{Na}$ década de 1970, o Brasil alcançou a posição de segundo maior parque naval mundial, atrás apenas da japonesa. A partir de 1980, uma forte crise intensificou por mais de uma década (JESUS e GITAHY, 2009).

A retomada das atividades da indústria de construção naval brasileira teve início no final da década de $90 \mathrm{com}$ políticas de apoio ao desenvolvimento da indústria, a ampliação e implantação de novos estaleiros, especialmente com a garantia de demanda pelos armadores Transpetro/Petrobras e subsídios de financiamento desembolsados Fundo de Marinha Mercante - FMM e foi acompanhado pelo volume de emprego.

Ocorreram grandes investimentos a partir da retomada com novos parques industriais, principalmente nos últimos 13 anos e em especial nos estados da Bahia, Espírito Santo, Pernambuco, Rio Grande do Sul e Rio de Janeiro (IPEA,2014).

Os centros de tecnologia e as redes pesquisa e inovação foram fundamentais na retomada da indústria no país. As expectativas que foram criadas com a exploração de petróleo da camada pré-sal elevaram ainda mais as projeções de carteira de encomendas que foi fortalecida com efetiva garantia de demandas da Transpetro/Petrobras. Além da retomada, também a visão de futuro de uma indústria naval efetiva que responda as demandas internas do país sem depender de 
tecnologia externa (Jesus, 2013) .O gráfico 02 a seguir demonstra os investimentos realizados FMM - Fundo de Marinha Mercante, para a construção de 350 embarcações e seis projetos em estaleiros.

Gráfico 02 - Evolução do desembolso do FMM - Fundo da Marinha Mercante

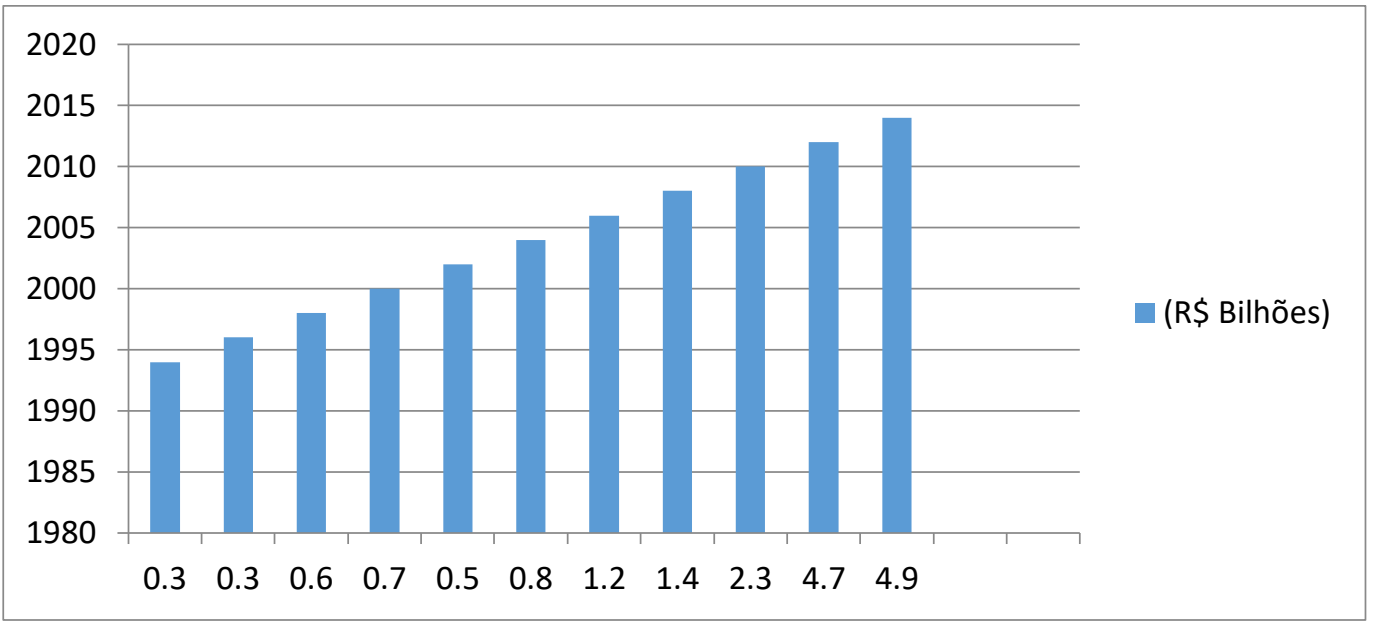

Fonte: Sinaval (2015) adaptado.

Em 2003, quando a Petrobrás, iniciou uma política de explícita de direcionamento aos estaleiros nacionais, ainda bastante sucateados, com baixa capacitação tecnológica e baixa produtividade de recursos humanos - resultado de anos de inatividade. As recentes descobertas na camada pré-sal da costa brasileira ampliaram 0 interesse pela indústria naval offshore no Brasil. O potencial das descobertas, em termos de volumes de encomendas e de possíveis impactos tecnológicos é considerado bastante expressivo. A Petrobrás e empresas nacionais anunciaram projetos de encomendas e investimentos com potencial para transformar o país em um dos maiores mercados de estruturas de produção offshore, assim como de embarcações de apoio. (FILHO, 2011).

A demanda em meados de 2014 apresentava uma carteira de 381 embarcações para estaleiros em diversas regiões do país de acordo com a Sinaval tabela 01 . Verifica-se que desta demanda $40 \%$ são embarcações de médio e grande porte ou estruturas offshore ligadas a exploração de petróleo. 
Tabela 01: Carteira de encomendas dos estaleiros brasileiros

\begin{tabular}{|c|c|c|}
\hline Tipo de Construção & Quantidade & Estaleiros Construtores \\
\hline Petroleiros & 34 & EAS (PE), Mauá (RJ) \\
\hline Gaseiros & 8 & VardPromar (PE) \\
\hline Sondas de Perfuração & 29 & ERG (RS), BrasFel (RJ), EJA (ES), Enseada (BA) \\
\hline Plataformas de Produção & 20 & BrasFels (RJ), ERG (RS), Brasa (RJ), Enseada (RJ) \\
\hline Navios de apoio marítimo & 61 & $\begin{array}{l}\text { BrasFels (RJ), Vard Niterói (RJ), Elsa (RJ), São Miguel (RJ), ETP (RJ), } \\
\text { Wilson Sons (SP), Naviship (SC), Detroit (SC), KeppelSingmarine (SC), } \\
\text { ERIN (AM), Intecnial (RS) }\end{array}$ \\
\hline $\begin{array}{l}\text { Navios porta - contêineres e } \\
\text { graneleiros }\end{array}$ & 4 & Eisa (RJ) \\
\hline Navegação Fluvial & 220 & Rio Maguari (PA), Rio Tiête (SP), ERIN (AM), EASA (AM), Intecnial (RS) \\
\hline Navios Patrulha & 4 & Eisa (RJ), Inace (CE) \\
\hline Submarinos & 5 & Estaleiro de Submarinos (RJ) \\
\hline Total & 381 & \\
\hline
\end{tabular}

Fonte: Sinaval (2014)

A crise econômica associadas a queda do preço do petróleo e os escândalos políticos envolvendo a Petrobras resultou cortes nos investimentos e cancelamentos de muitos projetos gerando nova crise no setor.

No processo de fabricação de embarcações a proteção das partes estruturas normalmente produzidas em aço é fundamental para garantir a integridade do material exposto ao ambiente marítimo de alto poder corrosivo. A pintura industrial é uma técnica de proteção anticorrosiva considerada uma tecnologia complexa, dinâmica, e bastante utilizada para superfícies metálicas tanto na construção naval bem como em muitos outros segmentos da indústria (OLIVEIRA, 2012).

O processo de tratamento de superfície e pintura de tanques é um dos principais gargalos na construção naval, podendo causar atrasos nas entregas pela sua complexidade, alta demanda de trabalho, baixo rendimento elevando o custo com maior uso de recursos.

Os tanques que constituem o tipo de embarcação que foi estudado correspondem mais de $55 \%$ de toda a área construída. Estas são áreas confinadas de difícil acesso com divisórias estruturais de aço (chamadas de cavernas) com pequenas aberturas dificultando a locomoção em seu interior e provocando uma serie de problemas ergonômicos aos colaboradores. As atividades de preparação e pintura da superfície das chapas ocorre após partes da embarcação já estar montadas, este ambiente é confinado, sem ventilação, sem iluminação, e de difícil locomoção, para executar as atividades o colaborador deve usar vários EPIs para evitar contato com produto químico, material em suspensão.

Este estudo de melhoria no processo de pintura de tanques na construção naval analisou as alternativas técnicas para eliminar estes problemas ergonômicos 
abordados. O desenvolvimento de uma solução que apresentasse viabilidade econômica e técnica .

O estudo foi realizado fabricação de tanques das embarcações de pequeno e médio porte construídos no estaleiro da Wilson Sons, situado na cidade do Guarujá/SP.

\section{EMPRESA ESTUDADA}

A Wilson Sons Estaleiros é uma empresa que atua há mais de 100 anos no mercado de médias e grandes embarcações, sua capacidade é de processar 10.000 toneladas de aço/ano.. Ao todo, mais de 150 embarcações foram construídas, entre as quais destacamos Rebocadores e Platform SupplyVessels (PSVs - embarcação de suprimento para plataformas de petróleo A empresa conta com duas unidades: 0 estaleiro Guarujá I, uma unidade ligada a exportação e ao setor de Óleo e Gás, com 20 mil $\mathrm{m}^{2}$ e tem capacidade para construção ou manutenção simultânea de embarcações de pequeno e médio porte, para apoio offshore e portuário, com 190 metros de comprimento por 16 metros de largura e o estaleiro Guarujá II, inaugurado em 2013, dobrando a produção de rebocadores e embarcações de apoio offshore, com um dique seco de 26 metros de boca e 145 metros de comprimento. Em 1998 a primeira no ramo naval com certificação de qualidade ISO 9000, pelo Lloyd's Register Quality Assurance. atualmente ISO 9001:2000. As categorias de embarcações fabricadas estão relacionadas com a função ou características da embarcação: PSVs (embarcação de suprimento para plataformas de petróleo), AHTS (embarcação para movimentação e posicionamento de âncoras e rebocagem oceânica), PSVS (embarcação para lançamento de tubulação e cabos submarinos), RSV (inspeção, manutenção e reparos), WSV (embarcação estimulação de poços) e ORSV (embarcação para recolhimento de óleo derramado).

\section{METODOLOGIA}

A metodologia utilizada para o desenvolvimento do trabalho foi com base em estudo de caso, utilizando as observações e levantamento de dados dos processos de construção de navios de apoio a plataformas e rebocadores construídos no estaleiro da Wilson Sons.

Através de visitas foi realizada a pesquisa exploratória de campo para coletar dados e informações, para entender os procedimentos e as normas que regem essa atividade e seus resultados a fim de melhorar a produtividade de tratamento e pintura nos tanques que compõe as embarcações. Foram utilizadas as técnicas de melhorias de processo como fluxograma para identificar oportunidades de melhoria no processo de tratamento e pintura antecipando a pintura de um holding primer na fase de construção dos blocos. Utilizando o Diagrama de Ishikawa (Causa - Efeito ) com colaboradores envolvidos no processo foram escolhidos para reuniões de Brainstorming foi possível levantar e visualizar graficamente quais eram as principais fatores (causas) que atuavam sobre o problema da baixa produtividade e demais itens relacionados como a ergonomia e segurança dos colaboradores quando o tratamento de superfície é feito nos tanques já edificados e prontos estruturalmente. Com acompanhamento de uma obra real de dois rebocadores idênticos em construção simultânea no produzido de forma convencional e outro com a modificação no processo. A alteração proposta foi realizar o tratamento e pré-pintura 
na fase de blocos antes da edificação. A comparação dos resultados entre as duas peças possibilitou quantificar os ganho na produtividade e nos custos envolvidos, além de possibilitar melhoria na ergonomia dos colaboradores.

\section{ANÁLISE E DISCUSSÃO}

\subsection{Processo existente}

A partir das especificações definidas no projeto e sua funcionalidade determina-se o sistema de pintura de acordo com as solicitações necessárias do armador e das condições operacionais do navio. O processo de construção do estaleiro foi estudado mapeado no fluxograma, apresentando todas as etapas de fabricação: Recebimento e preparação do aço, Chegada dos blanks ao estaleiro, Prémontagens dos painéis, Entrega na área de blocos, Construção e Montagem dos blocos, Virada do bloco, Içamento do bloco para o dique, Edificação dos blocos no dique, Realização dos testes aplicáveis: Estanqueidade, Radiografias e Ultrassom em soldas, Montagem de acessórios e Tratamento de superfície e pintura definitiva do tanque para liberação dos testes de sistema de carga e lastro (Fig.1 ).

Figura 1-Fluxograma até a liberação dos tanques para testes

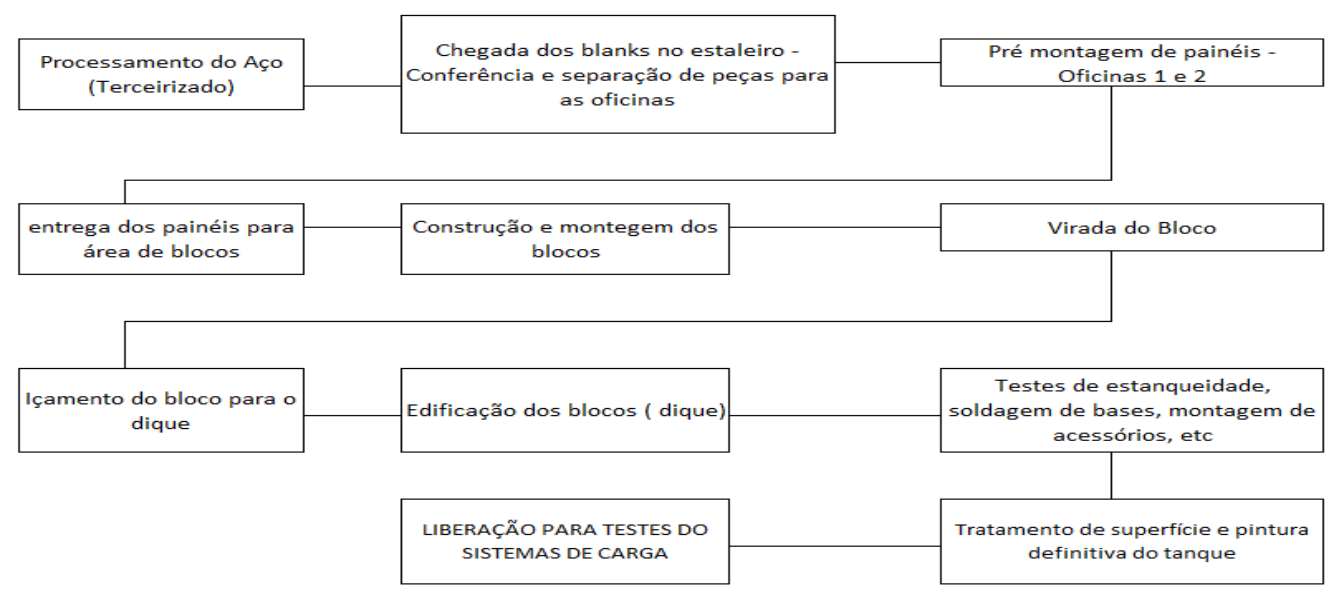

Fonte: Wilson Sons Estaleiros

\subsection{Tratamento de Superfície no Interior dos Tanques - Observações de Visita no Estaleiro}

No processo convencional os compartimentos eram liberados para fazer o tratamento de superfície e pintura com a parte estrutural dos tanques já edificada com todos os testes realizados: estanqueidade (teste realizado para verificara existência, ou não de vazamentos), inspeções de Raio X (ensaio não-destrutivo para verificar a existência de alguma falha interna ou descontinuidade no material) e ultrassom (ensaio não destrutivo baseado em ondas de ultrassom para detecção interna de defeitos em materiais ou para a medição de espessura de paredes e detecção de corrosão). Todos os blocos estavam edificados por completo, os equipamentos e tubulações montados e até mesmos os cabos elétricos na sua maioria já estão lançados. Todos os trabalhos a quente ou seja que envolvem soldas, cortes com maçaricos, deveriam estar concluídos na parte externa dos tanques, pois esses influenciam diretamente os trabalhos da pintura; Caso fosse 
necessário algum trabalho a quente no exterior do tanque após a pintura esta seria afetada. Sendo assim, o setor de pintura entra efetivamente na fase final para preparar a superfície e aplicar a tinta conforme o plano de pintura quando todos os trabalhos a quentes ao redor dos tanques estão terminados. Outras atividades são executadas nos compartimentos adjacentes enquanto a pintura ocorre dentro dos tanques, a maioria das áreas do navio como: sala de máquinas, compartimentos de carga e compartimento de propulsão. ( figura 2).

Figura 2 - Visão 3D - Praça de Máquinas

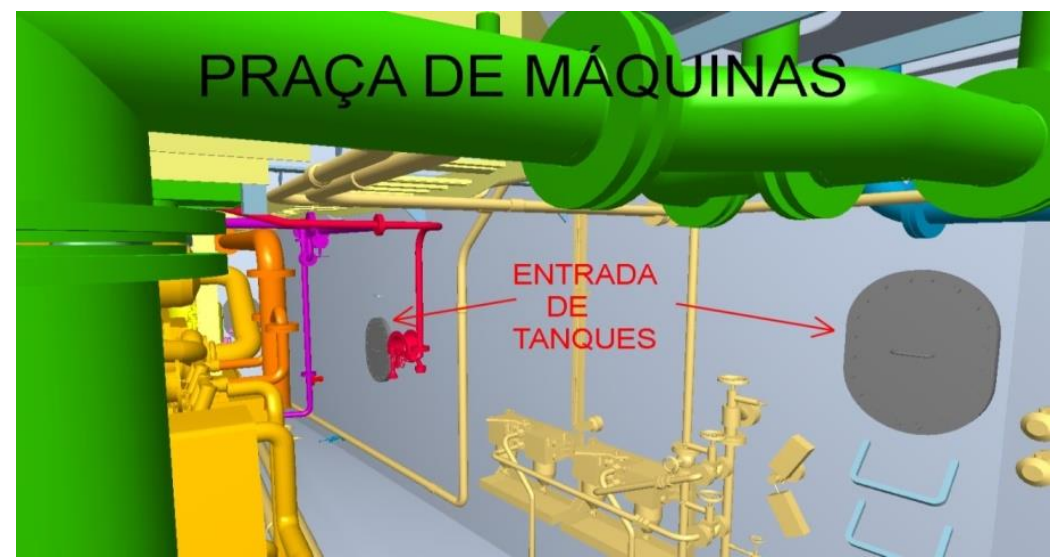

Fonte: Projeto Wilson Sons Estaleiros

Com o tratamento de superfície o ambiente fica com o elevado nível de partículas em suspensão devido a escovação do aço, para remoção da oxidação ou corrosão mais severo e estas partículas de a poeira tende a circular no compartimento ao lado depositando-se nos equipamentos como motores painéis elétricos e bombas sujando o ambiente e afetando as condições de trabalho dos colaboradores, gerando a necessidade do uso de mascaras para evitar a inalação de poeira (figura 3).

Figura 3 - Tanque sem tratamento e limpeza - oxidação mais severa na superfície.

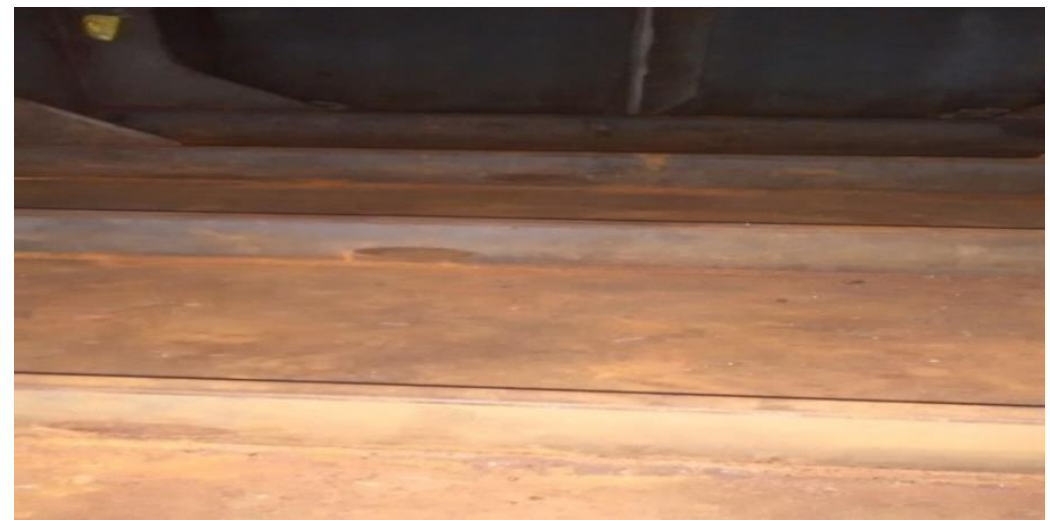


Figura 4- Dificuldade de acessar áreas para tratamento

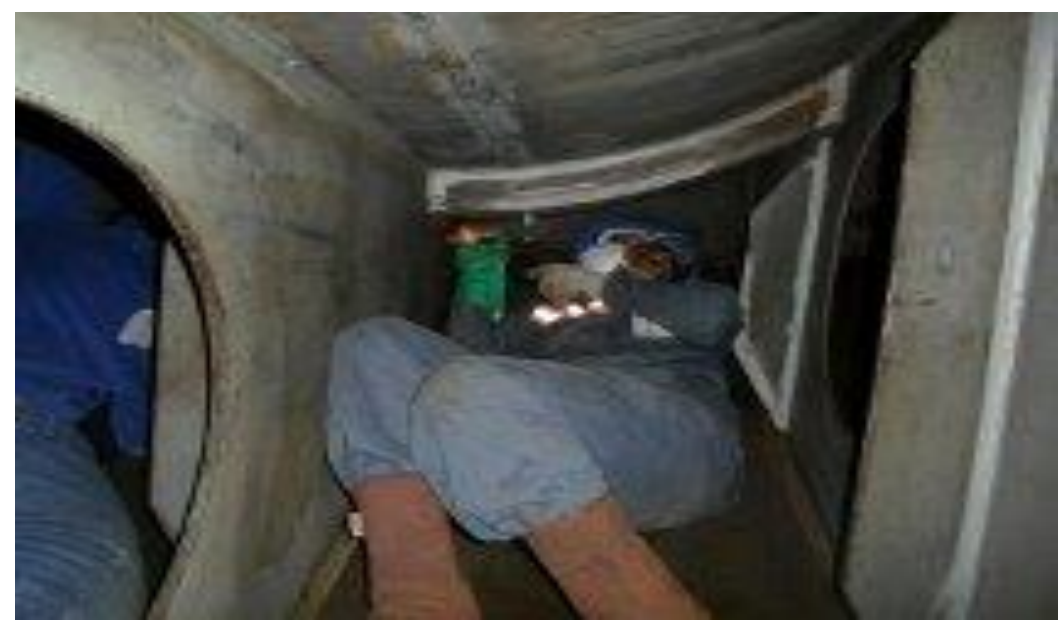

Fonte: Dos autores. (2016)

A locomoção e a movimentação para execução das atividades de tratamentos superficial, limpeza e pinturas são um aspecto extremamente crítico no processo são áreas confinadas e de difícil acesso (figura 4 e 5). Utilizam-se ferramentas manuais, equipamentos elétricos ou ferramentas pneumáticas como: lixadeiras, mangueiras de ar, pulmão de distribuição de ar comprimido e ventiladores. 0 transporte e o uso destes tornam o serviço mais. lento e provoca a fadiga,

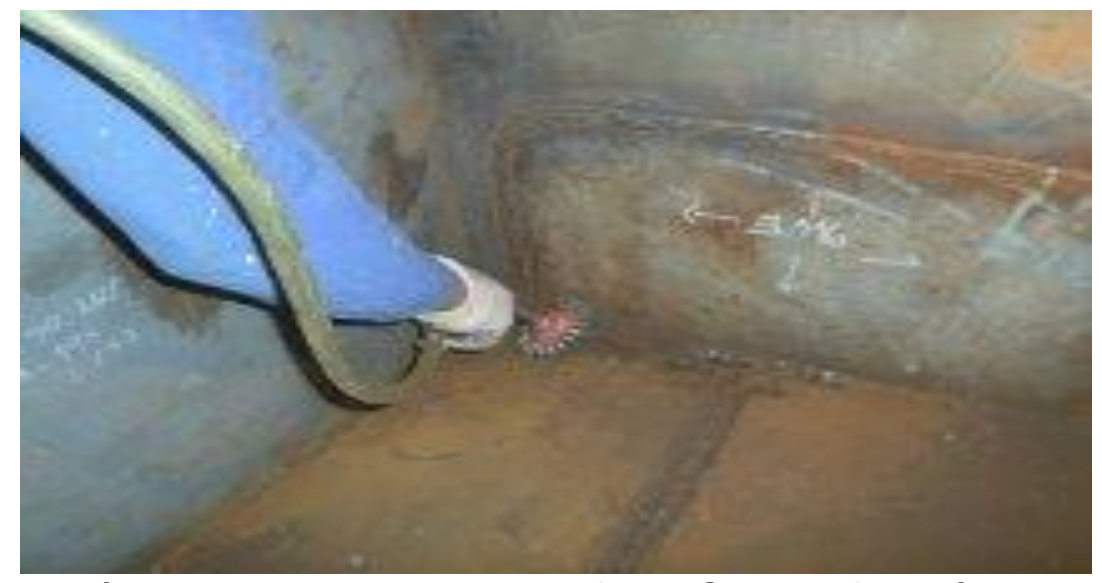

O acabamento é determinado por padrões. O padrão mínimo de superfície especificado é o St 3 - ISO 8501. Nem todos os cantos são possíveis de alcançar o padrão de superfície exigido usando somente a escova rotativa. Sendo assim, é necessário usar um desincrustador (agulheiro) para retirada da corrosão ou sujeira impregnada, tornando o processo ainda mais lento. Após atingir o padrão de superfície especificado é necessária realizar a limpeza remoção do resíduo mais grosso com vassouras de pelo e a poeira mais fina tem que ser aspirada em seguida o tanque deve ser limpo com panos embebidos em solvente para não haver oxidação superficial no aço exposto. Ao termino é feita liberação por um inspetor para execução da pintura. 


\subsection{Pintura no interior dos tanques}

As tintas especificadas em tanques são as chamadas primer/acabamento, ou seja, não é necessária aplicação de um primer anticorrosivo e depois o acabamento. Essa tinta possui a função de proteção anticorrosiva e acabamento. Conforme especificado no plano de pintura o tanque recebe a primeira camada geral (Full Coat) por meio de pistola airless, duas camadas de stripe coat (em cores diferentes) e por último a segunda demão geral. Na aplicação geral (full coat), o pintor deve entrar utilizando equipamentos de proteção individual, como: máscara de proteção facial com ar mandado, luminária a prova de explosão, pressão de ar positiva em seu macacão para que o gás da tinta não queime a pele nas áreas mais sensíveis do corpo como virilha e axilas. Antes da aplicação o pintor deve fazer um reconhecimento da área para identificar a complexidades, definir a rota de fuga e planejar onde será o início da aplicação para que os cabos e mangueiras que ele carrega não interfiram nem danifiquem a pintura (figuras 6 e 7).

Figura 6 - Colaborador com EPIs no local realizando reconhecimento

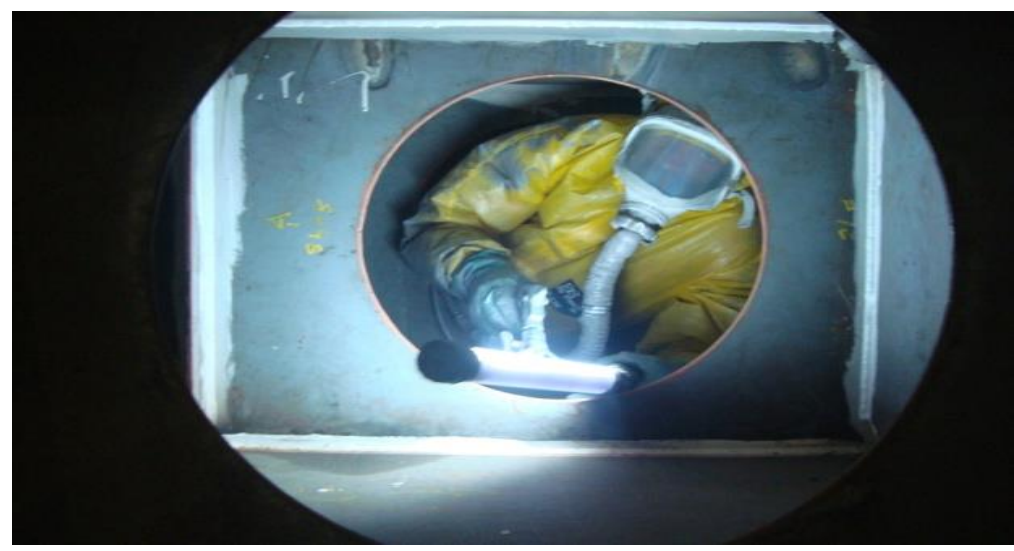

Figura 7 - local a ser pintado e seus acessos

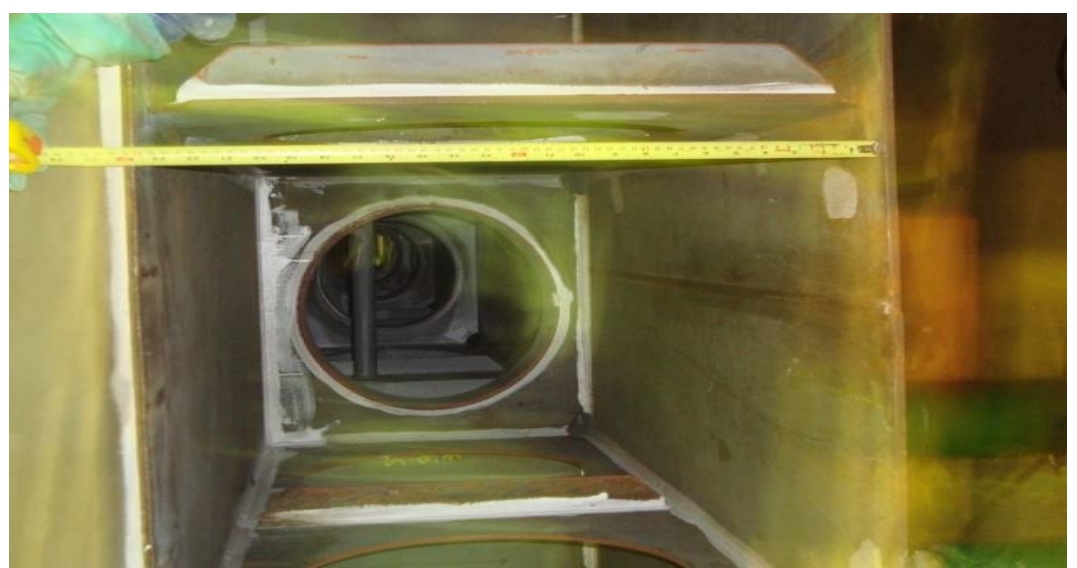

Fonte: Dos autores. (2016) 


\section{Análise do problema}

O uso do diagrama de causa e efeito possibilitou levantar as causas e identificar os problemas que influenciam na produtividade da atividade de tratamento de superfície no interior dos tanques.

Figura 8 - Diagrama de Ishikawa

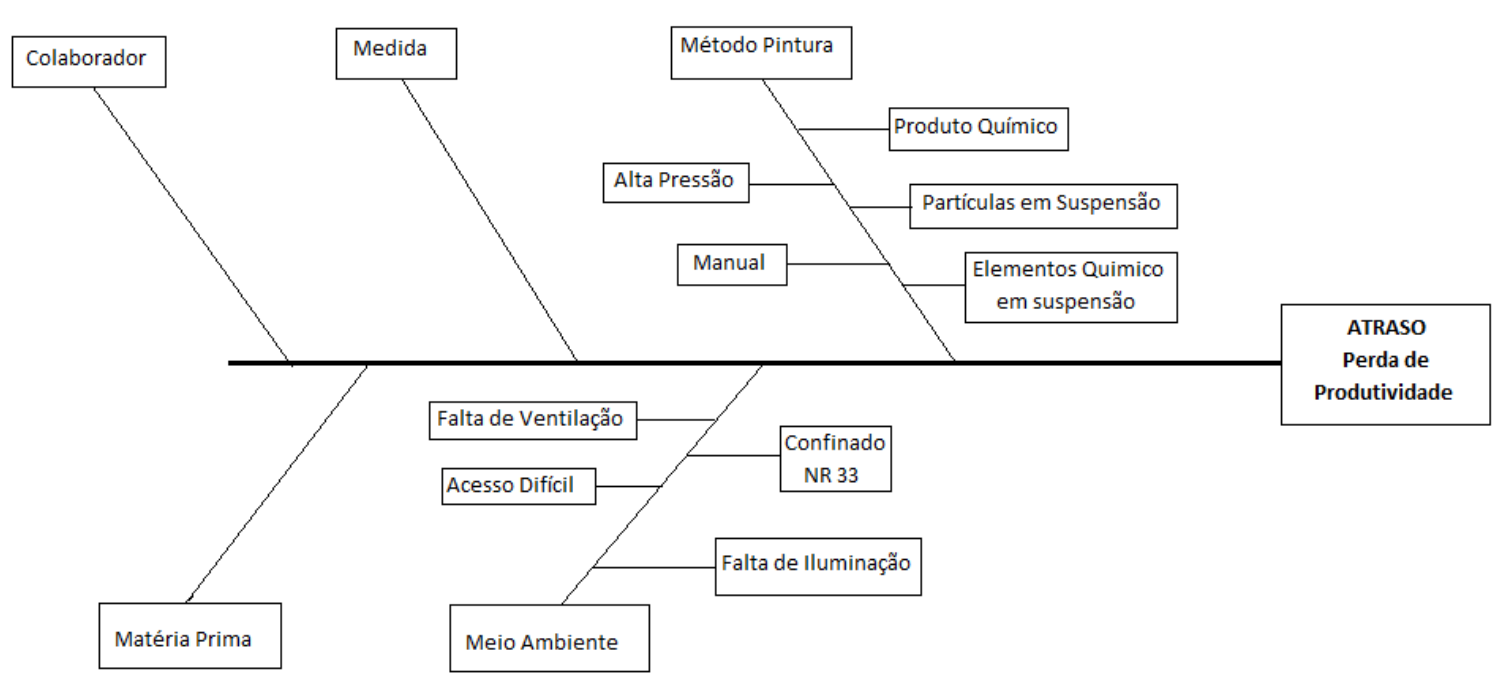

Fonte: Dos autores. (2016)

A análise do diagrama mostrou que dois fatores principais provocavam os efeitos sobre a produtividade estes fatores estavam associados ao processo e ao ambiente. Com a identificação das dificuldades enfrentadas para a tarefa foi possível buscar alternativas que poderiam viabilizar melhorias. Foi então proposto que na fase de blocos havia a possibilidade de antecipar a etapa de tratamento de superfície e realizar a aplicação de um holding primer (primer de espera), pois, nessa fase da construção a área a ser pintada está aberta facilitando todo o processo e melhorando as condições de trabalho dos colaboradores, além de proteger a superfície evitando a oxidação das peças expostas ao meio ambiente.

\subsection{Oportunidade de pintura na área de blocos - proposta de mudança}

A alteração do processo propondo a melhorar foi levada a administração. Houve uma reunião com o setor de pintura, projeto do estaleiro e os fabricantes de tintas para definir um produto (holding primer) que pudesse receber o esquema de pintura definitivo sem nenhuma interferência ou reação antes da montagem, ou seja, na fase de blocos. Por se tratar de esquema de pintura interna de tanque de carga principalmente destinado a água potável, foi necessário realizar uma avaliação na especificação do produto a aplicar como holding primer para evitar este a contaminação a água. Alguns fornecedores declinaram porém um dos fabricantes 
especificou um produto emitindo uma declaração (garantindo) não haver risco de contaminação na água. O produto especificado além de poder receber o esquema de pintura de todos tanques e compartimentos foi especificado para os tanques de óleo de serviço e óleo lubrificante como produto final. Esses tanques pintados na área de blocos foram retocados e feita limpeza para liberação dos testes. No escopo da pintura foi incluída um holding primer na fase de construção dos blocos. Com esta mudança o bloco foi direcionado pré-pintado para a edificação o processo de preparação de superfície tornando-se mais rápido e fácil. Depois de edificado somente será necessário tratado nas regiões onde houve queimas ou danos mecânicos para receber a pintura definitiva. São inúmeras as vantagens de fazer a preparação de superfície e pintura do holding primer nos blocos: a área não está confinada, a iluminação é natural (luz do dia) possibilitando melhor qualidade ao tratamento, não é necessária ventilação forçada na maioria dos casos, o aço não está oxidado devido ao shop primer ainda estar intacto, o colaborador tem mais espaço de locomoção melhorando a ergonomia, a logística das ferramentas e equipamentos torna-se mais fácil, reduzindo a fadiga . A figura 10 mostra o bloco da seção 112 do rebocador ainda aberto. Observa-se a chapa em bom estado sendo necessário fazer o tratamento somente nos cordões de soldas e nos danos mecânicos ocorridos na montagem. A figura 9 mostra alguns queimados e falhas que serão reparados pontualmente.

Figura 9 - Tanque de óleo de serviço pintado no bloco

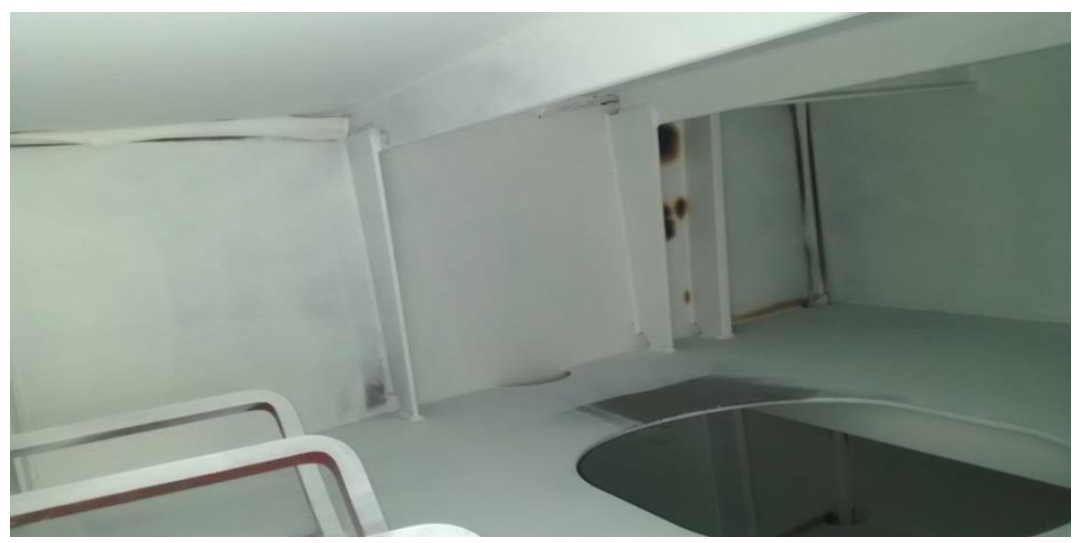

Figura 10 - Bloco da seção 112 do rebocador
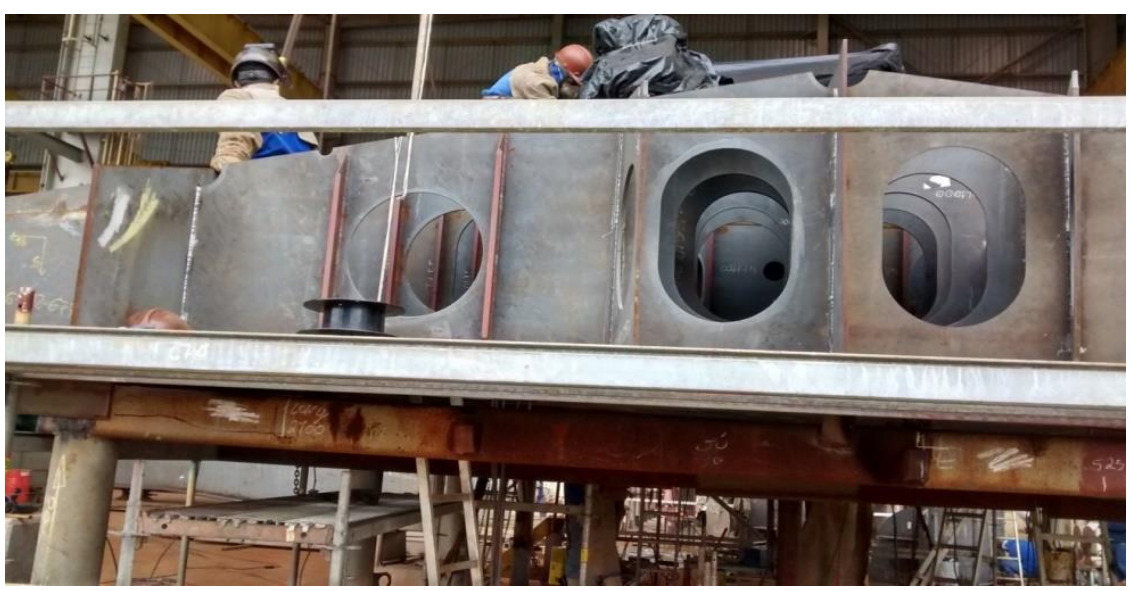

Fonte: Dos autores. (2016) 
Como o bloco é construído de cabeça para baixo é possível fazer um melhor tratamento no teto, pois nessa condição o teto é o piso antes da edificação. Quando edificado é necessário fazer o tratamento sobre cabeça, onde a dificuldade é maior. A figura 11 mostra o piso do bloco que depois de edificado passa a será teto de um tanque. Nota-se que a oxidação fica mais severa com o tempo e depois de edificado a tendência é ficar mais agressivo ainda dificultando o tratamento. Por tanto a antecipação do tratamento nesta fase reduz o trabalho devido à minimização da ocorrência de oxidação ficando menos intensa. É importante observar também na figura 11 que nessa fase a área está totalmente aberta melhorando a locomoção dos colaboradores.

Figura 11 - Teto do bloco antes da edificação, sem tratamento e pintura.

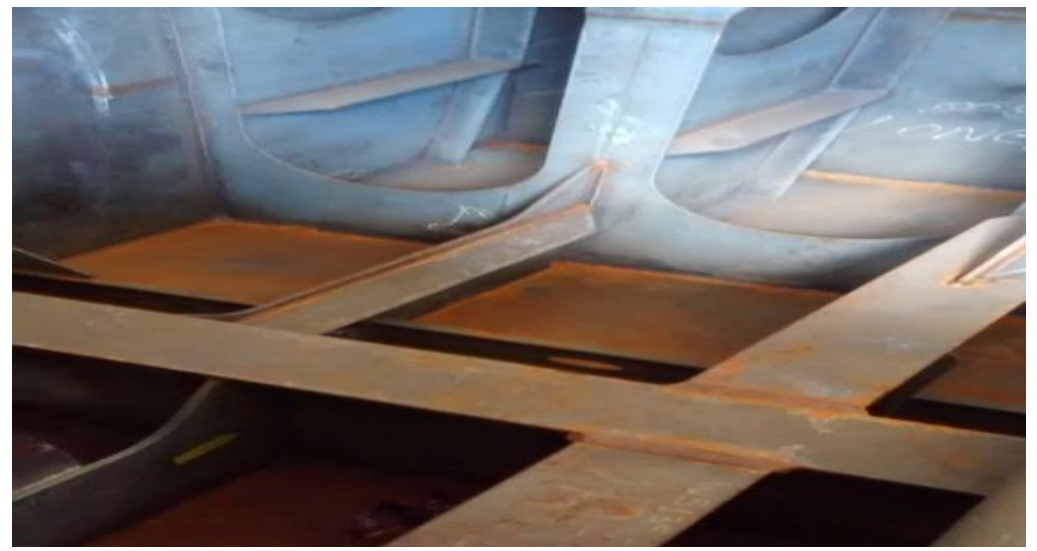

Figura 12 - Teto do bloco antes da edificação, após receber a pintura com o holding primer

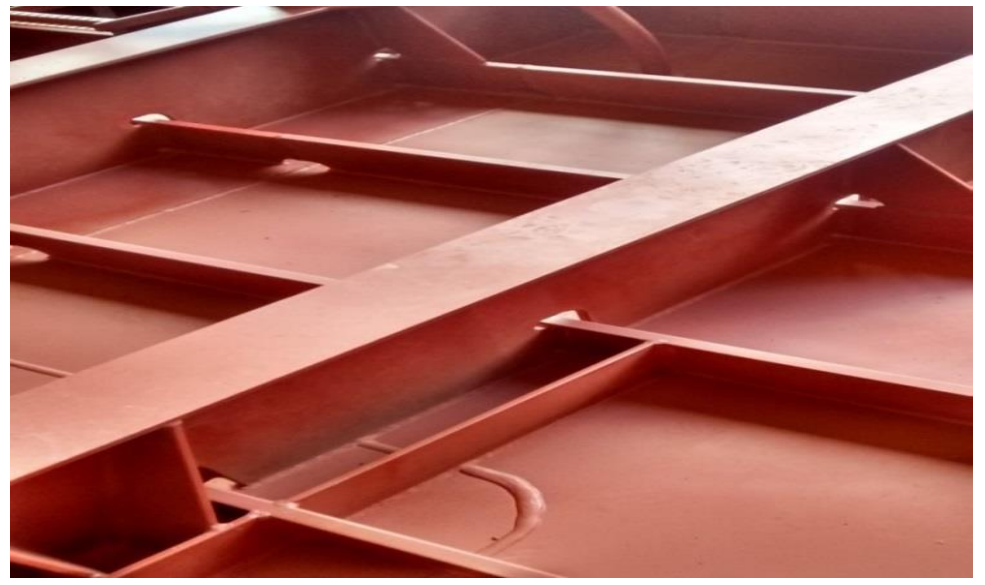

Fonte: Dos autores. (2016)

\subsection{Análise de dados}

Os resultados obtidos com a implementação da mudança no processo foram obtidos através da comparação de dois blocos idênticos (seção 112) de rebocadores construídos simultaneamente. Os blocos foram acompanhados até a completa edificação no dique e coletados os dados desde a liberação para pintura definitiva até a inspeção final. O casco WS-146 que foi produzido pelo método convencional, não foi pintado na área de blocos sendo tratado com a seção edificada, ou seja, com 
os compartimentos já definido e prontos e com estado de oxidação moderado dentro dos tanques ( figura 13).

Figura 13 -Tanque sem tratamento e pré-pintura

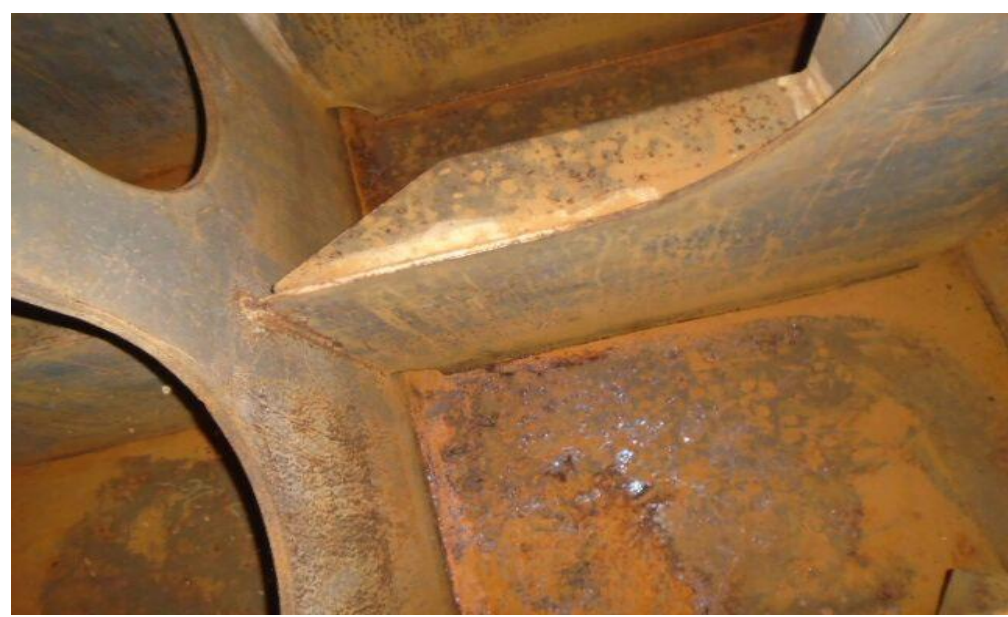

Fonte: Dos autores. (2016)

Abaixo a figura 14 mostra o desenho dos blocos que contemplam um rebocador e a figura 37 ilustra em 3D o bloco da seção 112 (bege) em corte onde é possível notar as cavernas de todos os tanques que compõe essa seção:

Figura 14 - Desenho dos blocos que contemplam um rebocador

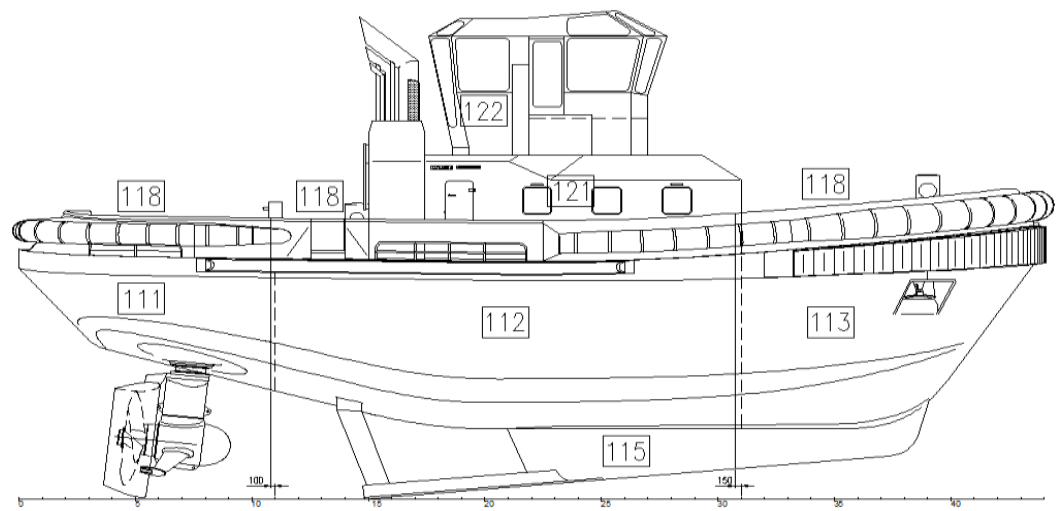

Fonte: Wilson Sons Estaleiros 
casco WS-147 que foi produzido pelo método proposto, recebendo pintura do holding primer no bloco antes da montagem, sendo edificado com pré-pintura e concluindo o tratamento de superfície sem oxidação como mostra a figura 15.

Figura 15 - Tanque com pré-pintura (holding primer)

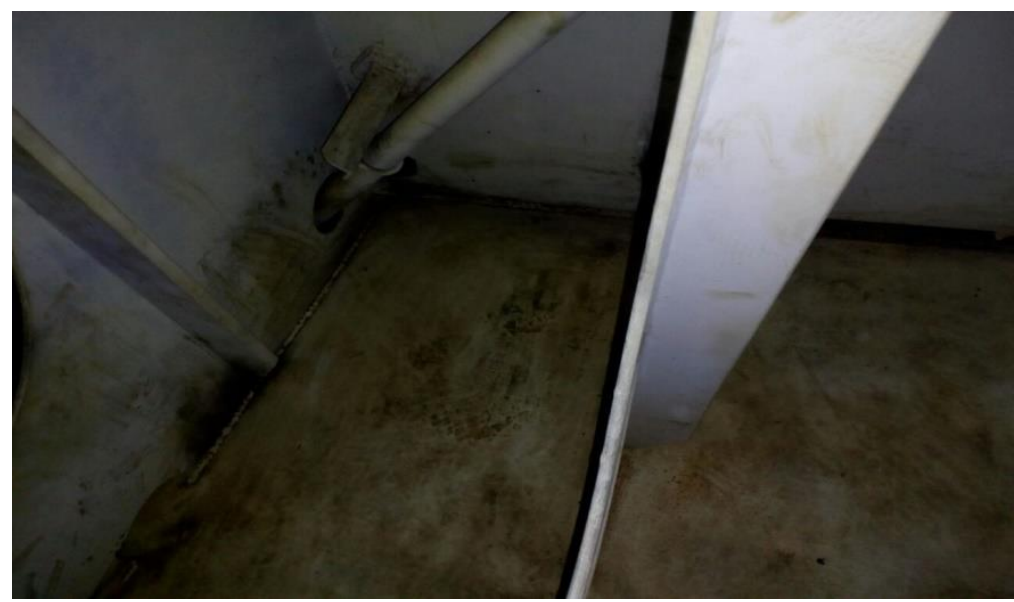

Fonte: Dos autores. (2016)

A superfície está isenta de oxidação, os resíduos proveniente de trabalho a quente devem ser removidos com panos umedecidos com água e queimados na parte externa do tanque.

\subsection{Resultados Obtidos}

Na seção do WS-146 que foi produzido pelo método convencional, consumiu a quantidade de horas e os custos de $\mathrm{H} / \mathrm{h}$ para pintura definitiva dos tanques essa seção, bem próximas do planejado, ou seja, foram planejadas 266,1 horas e foram gastas 247,5 horas para finalizar os tanques com o esquema de pintura definitivo. A seção do WS-147 que recebeu tratamento e pintura na área de blocos foi construída e pré-pintada com holding primer em uma empresa terceirizada onde foram gastas 63 horas e teve um custo total entre mão de obra e materiais de $R \$ 3.547,20$. Somando as horas gasta pela terceirizada para o tratamento e pré-pintura da seção 112 adicionando as horas gastas no estaleiro para finalizar a pintura dos tanques depois de edificado totalizou de 202,3 horas. A diferença entre processos em horas representa $22,3 \%$ a menos em comparação a seção que não recebeu o prétratamento. Os custos totais somados entre a terceirizada e o estaleiro totalizou de 
$R \$ 12.431,02$. Portanto, houve uma diminuição de $13,93 \%$ nos custos entre materiais e mão de obra dos tanques pré-pintados na área de bloco se comparados aos que não passaram pelo processo proposto. Abaixo as tabelas 5 e 6 comparativas .

Tabela 05 - Horas planejadas e realizadas

\begin{tabular}{|c|c|c|c|c|}
\hline Atividade & $\begin{array}{c}\text { Horas } \\
\text { Planejadas }\end{array}$ & $\begin{array}{c}\text { Horas Realizadas } \\
\text { WS-146 } \\
\text { (Convencional) }\end{array}$ & $\begin{array}{c}\text { Horas Realizadas } \\
\text { WS-147 } \\
\text { (Proposto) }\end{array}$ & Ganho \\
\hline Tratamento & 219,1 & 214,1 & 170,5 & $25,57 \%$ \\
\hline Pintura & 47 & 33,4 & 31,8 & $5,03 \%$ \\
\hline Total & $\mathbf{2 6 6 , 1}$ & $\mathbf{2 5 7 , 5}$ & $\mathbf{2 0 2 , 3}$ & $\mathbf{2 2 , 3 5 \%}$ \\
\hline
\end{tabular}

Tabela 06 - Custo Planejado x Realizado

\begin{tabular}{|c|c|c|c|}
\hline $\begin{array}{c}\text { Custos } \\
\text { Planejados }\end{array}$ & $\begin{array}{c}\text { Custo Realizado } \\
\text { WS-146 } \\
\text { (Convencional) }\end{array}$ & $\begin{array}{c}\text { Custo Realizado } \\
\text { WS-147 } \\
\text { (Proposto) }\end{array}$ & Ganho \\
\hline $\mathrm{R} \$ 14.510,31$ & $\mathrm{R} \$ 14.163,20$ & $\mathrm{R} \$ 12.431,02$ & $\mathbf{1 3 , 9 3 \%}$ \\
\hline
\end{tabular}

Fonte: Dos autores. (2016)

\section{Considerações finais}

Os resultados comparativos dos blocos identicos da seção 112 dos cascos WS-146 e WS-147 comprovaram eficiência do metodo proposto diminuir $22,35 \%$ das horas para execução da atividade e uma redução de 13,93\% nos custos envolvendo materiais e mão de obra.

O aspecto mais importante foi melhorar as condições ergonômicas dos colaboradores e os riscos inerentes a execução da tarefa em espaço confinado.

Os benefícios com a implantação desse projeto irá melhorar a produtividade no processo de tratamento e pintura dos tanques do qual correspondem a aproximadamente $55 \%$ da área total do navio. A pré-pintura dos blocos sendo feita antes do aço estar em processo de corrosão quando já edificado, diminui a poeira gerada pelo escovamento da superfície proporcionando melhores condições para os setores que trabalham paralelamente nos compartimentos adjacentes, melhorando as condições ambientais com a redução de partículas suspensa no ar. 
A alteração proposta reduziu os custos contribuindo para reduzir o prazos de entrega.

\section{REFERÊNCIAS}

CASTRO, Luciano Vicenconte. Qualidade da Pintura na Construção Naval. 2009. 65 f. Projeto Final de Curso - Rio de Janeiro, 2009. Disponivel em: $<$ http://www.oceanica.ufri.br/intranet/teses/2009 graduando luciano viceconte.p df> Acesso em 05 Set. 2016.

GENTIL, V., Corrosão, 4.ed., Rio de Janeiro: Livros Técnicos e Científicos, 2005.

JESUS, C. G. Retomada da Industria de Construção Naval Brasileira. 2013. Disponivel em: http://www.bibliotecadigital.unicamp.br/document/?code $=000905896$ Acesso em 23 Ago. 2016.

Jotun. Disponivel em: http://www.jotun.com/ Acesso em 10 Set. 2016.

KIM, H. T., LEE, J. K., PARK, J. H., PARK, B., \& JANG, D. S. (2002). Applying Digital Manufacturing Technology To Ship Production And The Maritime Enviroment.

LAMB, T., M., S., J., S., J., W., \& P., K. (2003). Simulation Based Performance Improvement For Ship Building Processes.

MUNGER, C. G. (1999). Corrosion Prevention by Protective Coatings.

NUNES, L. d., \& A.C.O.LOBO. (1998). Pintura Industrial na Proteção Antuicorrosiva.

OLIVEIRA, A. R. (2012). Corrosão e Tratamento de Superficie.

Pinceis Tigre. Disponivel em: <http://www.pinceistigre.com.br/> Acesso em 06 Jul. 2016.

Wilson Sons Estateiros. Disponivel em: www.wilsonsons.com.br Acesso em 03 Jun. 2016. 